\title{
Experience With Synchronous and Asynchronous Digital Control Systems
}

Victoria A. Regenie, Claude V. Chacon, and Wilton P. Lock

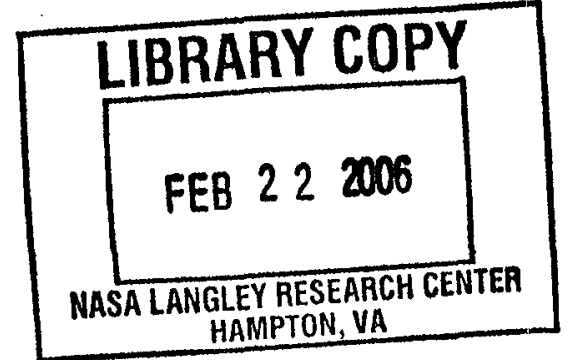

\section{N/SA}

National Aeronautics and

Space Administration 
NASA Technical Memorandum 88271

\section{Experience With Synchronous and Asynchronous Digital Control Systems}

Victoria A. Regenie, Claude V. Chacon, and Wilion P. Lock Ames Research Center, Dryden Flight Research Facillty, Edwards, California

\section{N/Sก}

National Aeronautics and

Space Administration

Ames Research Center

Dryden Flight Research Facility

Edwards, California 93523-5000 
EXPERIENCE WITH SYNCHRONOUS AND ASYNCHRONOUS DIGITAL CONTROL SYSTEMS

Victoria A. Regenie,* Claude V. Chacon, ** and Wilton P. Lock**

NASA Ames Research Center

Oryden Flight Research Facility

Edwards, California

\section{Abstract}

Flight control systems have undergone a revolution since the days of simple mechanica? linkages; presently the most advanced systems are full-authority, full-time digital systems contralling unstable aircraft. With the use of advanced control systems, the aerodynamic design can incorporate features that allow greater performance and fuel savings, as can be seen on the new Airbus design and advanced tactical fighter concepts. These advanced aircraft will be and are relying on the flight. control system to provide the stability and handling qualities required for safe flight and to allow the pilot to control the aircraft. Various design philosophies have been proposed and followed to investigate system architectures for these advanced flight control systems. One major area of discussion is whether a multichanne 1 digital control system should be synchronous or asynchronous. This paper addresses the flight. experience at the Dryden Flight Research Facility of NASA's Ames Research Center with both synchronous and asynchronous digital flight control systems. Four different flight control systems are evaluated against criteria such as software reliability, cost increases, and schedule delays.

\section{Nomenciature}

AFTI advanced fighter technology integration

CAS control augmentation system

CBS computer bypass system

DFBW digital fly-by-wire

OEFCS digital electronic flight control system

HiMAT highiy maneuverable aircraft technology

$1 / 0$ input-output

IPCS integrated propulsion control system

I.VDT linear variable differential transducer

REBUS resident backup software

RPRV remotely plloted research vehicle

SAS stability augmentation system

Introduction

Flight control systems have undergone a revolution since the days of simple mechanical linkages; presently the most advanced systems are full-authorlty, full-time digital systems

\footnotetext{
*Aerospace engĩneer. Member AIAA.

**Aerospace engineer.
}

controlling unstable aircraft. To allow the most flexibility in aerodynamic design, both military and commercial aviation programs are incorporating digital flight control systems in aircraft design. With the use of advanced control systems, the aerodynamic design can incorporate features that allow greater performance and fuel savings, as can be seen on the new Airbus design and advanced tactical fighter concepts. These advanced aircraft designs will be and are relying on the flight control systems to provide the stability and handling qualittes required for safe flight and to allow the pilot to control the aircraft. As the criticality and number of these control systems increase, it becomes increasingly important to understand issues related to the development of a system that will provide maximum protection with minimum cost and minimum maintenance. Various design philosophies have been followed and proposed related to system architectures for these advanced flight control systems.

One major area of discussion is whether a multichannel digital control system should be synchronous or asynchronous. Asynchronous systems are propounded to provide greater protection against lightning and electromagnetic compatibility interference. These systems are also expected to provide greater battle damage protection. Synchronous systems are said to be more reliable and to provide lower design and test costs. A majority of the digital flight control systems that have been flown are synchronous; oniy a few are asynchronous. Examples of synchronous digital flight control systems include the F-8 digital fly-by-wire (DFBW), F-18, F-15 digital electronic flight control system (DEFCS), and forward-swept-wing $X-29 A$. Asynchronous systems include the advanced fighter technology integration (AFTI) $F-16$ and the resident backup software (REBUS) system, an experimental backup system for the F-8 DFBW aircraft. Both the United Kingdom and Sweden have flown asynchronous digital flight control systems as well as the more conventional synchronous systems.

The Dryden Flight Research Facility of NASA's Ames Research Center (Ames-Dryden) has experience with both synchronous and asynchronous digital control systems on advanced high-performance aircraft. The first digital fly-by-wire aircraft, the F-8 DFBW, developed and flown at Ames-Dryden in the mid-1970s and still in use as a research vehicle, includes a triplex synchronous digital flight control system. The REBUS system, an experimental dissimilar backup system incorporated in the F-8 DFBW primary flight control system, consists of three asynchronous elements. The highly maneuverable aircraft technology (HiMAT) vehicles (subscale, remotely piloted research vehicles (RPRV) flown at Ames-Dryden in the late 1970 s and early 1980s) included 
advanced aerodynamic configuration and advanced technological concepts (such as digital engine and flight control) and used synchronous and asynchronous systems combining ground and onboard com puters. The AFTI/F-16 aircraft, currently flying at Ames-Dryden, is an F-16 afrframe with a dorsal fairing (to house instrumentation) and vertical canards (for advanced flight control application) added; it is controlled by a triplex asynchronous digital flight control system. These represent a range of digital flight control systems, from very simpie to highly complex. The systems have employed various levels of redundancy, ranging from one sensor to six identical sensors.

This paper describes flight experience at Ames-Dryden with bot:h synchronous and asynchronous digital flight control systems. The unusual architectures of the F-8 DFBW, HIMAT, AFTI/F-16, and REBUS systems are discussed and evaluated. Benefits and deficiencies for both types of archi.. tectures are discussed, and any conclusions that can be made from the filight data are included.

The authors would like to thank Kenneth $\mathrm{J}$. Szalai, Robert $W$. Kemple, Dwain A. Deets, Stephen D. Ishmael, and Capt. Mark L. Joyner for their previous work in this area.

\section{Is sues of Asynchronous} and Synchronous Systems

The majority of digital flight control systems currently operating are synchronous. The systems are synchronized through a combination of hardware and software. At specific points in the software an instruction triggers a hardware circuit to send a discrete signal to other identical computers, called channels. Each channel receives this synchronization signal and begins to process specified software. Thus, each channel is operating at the same point in the software cycle at any given time. If the synchronization signal is not received within predetermined time constraints, the channigl transmitting the synchronization signal is detlared falled, as are all the data it transmits. The system can be synchronized at different levels, such as once each frame or at any subframe. Data in synchronous systems are passed during specific time periods, and the other channels expect to receive these data at the proper time. If the data are not received when expected, the transmitting channel is declared falled. The synchronization period is determined by the digital flight control system requirements.

Asynchronous systems operate without a synchronization signal. Even though each digital flight control system channel is identical, with the same clock rates and initialization point, small differences between channels occur because of hardware tolerances. The skew (or timing differences between channeis) varies, and each channel can be operating at any point in its software cycle at any given time. In asynchronous systems, data are passed when avallable, and the other channels access the data when they are ready. The health of other channels is determined by data comparisons and other information from the other channels.

The decision concerning whether the digital flight control system will be synchronous or asynchronous impacts the design of the control laws and redundancy management functions. Conversely, the requirements for the redundancy management functions and control laws impact the system architecture decision. The types of inputoutput $(1 / 0)$ selection and monitoring and the tolerance windows (the amount a signal can vary from other like signals and the length of time it can remain different before it is declared failed) for failure detection depend on whether the system is synchronous or asynchrounous. The tolerance windows for fallure detection must be larger for asynchronous systems to account for skew differsystems can use the synchronization signal, but asynchronous systems must use a different method, such as tolerance windows or number of output fallures. The type of data to be transferred and how often they will be transferred also need to be considered in the system architectural design. The capability of a system to reset or restart can also impact and be impacted by the system design. The control laws will rely on the system architecture in terms of the accuracy of the data they will be using.

Each of the two system design concepts, asynchronous and synchronous, has advantages and disadvantages. For synchronous systems, advantages include ease of verification and validation, ease of failure detection, and predictability; disadvantages include reliance on other channels and additional software and hardware requirements for synchronization. For asynchronous systems, advantages include channel independence and reduced hardware; disadvantages include unpredictability, difficulty in verification and validation, and more complex software for failure detection. These advantages and disadvantages can be evaluated in terms of reliability, costs, and schedule delays.

Reliability, which can be defined as the inverse of the number of in-flight nonnutsance fallures, is a critical parameter in flight safety or mission completion and can also have considerable effect on cost and schedule. Cost and schedule can be evaluated through the development cycle for the digital flight control system, including verification and validation time and flight operation. Delays in the schedule caused by design problems discovered during preitminary testing increase the cost of the program, as do verification and validation testing problems. Any problems discovered in flight during the flight test portion of the program, especially those connected to flight-critical functions, have considerable impact on reliability, cost, and schedule for the program. Any problems requiring extensive redestign discovered during the verification and validation or flight test portion of a program have major impacts on the program. Problems discovered in the operational environment have a major impact on the cost of the system, often causing the aircraft to be grounded until the problem is fixed. However, operational problems are not discussed in this paper, because the experience at Ames-Dryden is with experimental aircraft, not operational aircraft.

\section{Aircraft Systems Descriptions}

Short descriptions of the F-8 DFBW, REBUS, HiMAT, and AFTI/F=16 flight control systems are 
presented to provide a background for the results and conclusions. The F-8 DFBW, REBUS, and AFTI/ F 16 digital flight control systems are described in more detafl in Refs. 1 to 4. A detalled description of the HiMAT system is to be included in a NASA report, "Flight Control Systems Development and Flight Test Experience with the HIMAT Vehicles," by Robert $W$. Kempel and Michael $R$. Earls (In preparation). The effects of the system's architecture (synchronous or asynchronous) are included with the descriptions to provide a greater understanding of the test results and thus the evaluation of the two architectures. The software cycle, frame time, and control law complexity are described. Other major elements of the digital flight control system, such as $1 / 0$ selection and monitoring, self-test capability, reset-restart capabtlity, and control law modes, are also described.

\section{F -8 DFBW}

An F-8 aircrafi (Fig. 1) was modified to include a fall-operate, fail-safe, fly-by-wire flight control system that consists of a fullauthority, triplex, frame-synchronized digital system with a triplex analog computer bypass system (CBS) as backup. The flight control system (Fig. 2) encompasses triply redundant input motion sensors and controllers, triple interface units, cockpit controls and displays, and secondary actuators. The flight control computers operate the basic loop in $20 \mathrm{msec}$. The input and output signals for this synchronous system are processed through the interface units (one for each digital channel). The channels do not transfer data directly to the other channels, which avolds timing problems associated with transmitting and receiving data simultaneously. The interface units provide signal conditioning and buffer memory for all input data, process output signals, provide interchannel communication, and participate in the failure detection and redundancy management functions. The buffer nemory in the interface units consists of data from each channel, one buffer per channel per interface unit, which allows each computer to have access to the other channels' data. The synchronous operation of the system assures that each charnel is operating on the same data at the same time. The pilot control panels allow the pilot to select control modes for each axis and to select autopilot capabilities, while the display panels annunciate system status and fallure information. The CBS provides actuator controls for backup control, selection logic, and output fallure detection and provides an analog link from the pilot controls. The secondary actuators on the F-8 $\mathrm{CFBW}$ aircraft are triply redundant and contain three independent electrohydraulic channels with independent hydraulic fluid, differential pressure sensors, and linear variable differential transducer (LVDT) position sensing.

The F-8 DFBW aircraft does not require a complicated control system for stability augmentation, but for experimental purposes, pitch and lateral-directional stability augmentation system (SAS) modes were developed. The pitch axis mode also includes a more complicated control augmentation system (CAS) mode. A direct mode, which duplicates the unaugmented F-8 system for pitch, is also provided, as well as an autopilot for altitude hold, Mach hold, and heading and turn control. The inner-loop control law functions are computed at a $20-m s e c$ frame rate, while gain updating and autopilot functlons operate at a rate of $80 \mathrm{msec}$ per frame. The pitch CAS and the lateral-directional SAS contain scheduled rate gain and accelerometer feedbacks with forward-loop integrators. The control laws were designed to be complicated enough to investigate the interactions between the control laws and the redundancy management functions in a synchronous system.

The redundancy management and fault detection portion of the F-8 OFBW software selects the midvalue of three good sensors or the average of two good sensors after a single failure. If two like sensors have failed, a default value is used, and the function or mode requiring the failed-sensor information is inhibited, resulting in the loss of capability or mode. This function is performed on all vital input sensors, such as motion sensors and control inputs. The CBS monitors output commands using a midvalue selection technique and also compares the midvalue to the channels' actual values. If a failure is detected in the output, the analog channel is switched in to replace the failed digital channel. A second failure of a digital channel transfers all channels to the analog system. As a synchronous system, the $F-8$ DFBW computer system uses its sync discrete and the channel's data transfer capabllities, the data transmitted at the correct time, to verify the health of the digital channel. A self-test capability is included in the system to allow the computers to determine their own health and status. An automatic restart capability is included in the system design to initialize the channels at initial power up and in the event of powdr disruptions, crosslink fallures, or selftest fallure detection.

REBUS

An experimental dissimilar backup system, REBUS (Fig. 3), was incorporated into the F-8 DFBW system to investigate the concept of dissimllar software as backup for the primary system. To include software dissimilar from the synchronous F-8 DFBW system, the REBUS system is asynchronous, operating at a 20 -msec frame rate. Each of the triplex REBUS channels operates on dedicated sensors, with the channelsensor unit independent of the operation of the other units to avoid asynchronous data crossstrapping problems; each channel operates on slightly different input due to computer skew, The control laws provide minimal augmentation, ifttle more than the capability to return to base and safely land. Three-axis fixed-gain rate damping with some nonlinear stick shaping and deadbands comprise the control law design. The REBUS system does modify the gains for landing and approach, but the up-and-away gains are constant throughout the flight envelope. Transfer to the REBUS system from the primary system occurs as a result of channel failures. The REBUS software is initialized using a full complement of sensor inputs and existing control surface commands. 
HIMAT

The HiMAT vehtcles were air launched from a B.-52 aircraft and remotely controlled by a pllot located in a ground cockpit (Fig. 4). The primary control Jaws were resident in a ground-based computer with the backup control system included in the onboard backup computer. The onboard computers operatied asynchronously with the ground system and each other. The backup system could be controlled from efther the ground or a TF-104 chase aircraft.

The advanced concepts included in the HIMAT experiment were composite and metallic structures, close-coupled canards, aeroelastic tailoring, digltal integrated propulsion control system (IPCS), relaxed static stability, and ground and airborne digital fly-by-wire controls. The design maneuverability goal, a sustained 8-g turn at Mach 0.9 and an altitude of $25,000 \mathrm{ft}$, was achieved during flight test along with sustained supersonfc flight. Dual onboard computers, operating asynchronously, provided the inter. faces with the ground and vartous vehtcle subsystems, and each provided independent capabtlity for a safe return. The system also included dual electrical, hydraulic, and flight control systems (designated as primary control system and backup control system) as well as triplex angular rate sensors for all three axes, triplex lateral and normal accelerometers, and duplex air data sensors (Fig. 5). A single sensor of each variety was desitgnated as backup sensor, and only it was used by the backup control system; the primary system used all the sensors. The servo actuators were interfaced to the onboard computers through a servo actuator electronics box. which translated the servo commands, fed back the actuator data. and provided fallure detection for the elevon servo actuator system.

The HIMAT vehfcies were tested in two configurations, one with relaxed static stability and one with positive stability margins. The stable conflguration control laws were fullauthority rate-damper systems. The control system included a launch mode to assure separa$t i o n$ from the carrier aircraft and a degraded primary mode, which was selectable by the ground pllot and allowed the pilot to maintain conventional control for conditions such as loss of power in an engine-out situation. The pilot was given the option of choosing the degraded primary mode or the backup control system.

The backup control systen for the stable afreraft contained a variety of automatic modes to ensure recovery of the HiMAT vehicle from unusual or extreme conditions and to provide a safe return capability. The backup control system was also capable of orbiting at a specifted altftude when there was a loss of uplink or downlink signal. The backup control system was a multirate system operating at $10-, 20-$, and $100-m s e c$ frame rates. The onboard computer system also provided total contirol of the HIMAT engine with the primary IPCS resident in the backup computer and the backup IPCS included in the primary computer. The IPCS included a normal operation mode, a combat mode. and a high-stability mode.
In the relaxed-stability operation, a fixedgain pitch rate feedback loop was included in the onboard primary control syster to reduce excessive system time delays. As in the stable condition, the primary control system included a launch mode and degraded primary mode. The backup control system for the relaxed-stability operation contained seven modes (1 isted in Table 1) and was a full-authority, three-axis, multirate system. The backup control system was always initialized through the recovery mode, which brought the aircraft to a straight-and-level flight condition. once the HiMAT vehicle was in a straight-andlevel flight condition, the backup control system would transition to heading hold mode and alt itude hold mode. If no other command was received by the heading hold mode or altitude hold mode within $25 \mathrm{sec}$, the backup control system would transition to the orbit mode. Airspeed hold mode and landing mode were also included in the baskup control system.

The asynchronous interactions of the airborne system with the ground system and the ground rule that no single failure would result in loss of the veitcle resulted in a complex design for the HIMAT flight systems managenient functions. Data transfer was minimized by allowing each computer to operate independent functions that required little or no data exchange. The faults detected by the onboard computer system included those that caused automatic transfer to backup mode, those that prevented automatic transfer to backup mode, those that indicated mission abort conditions, and those that indicated caution conditions. The onboard computer fault detection included actuator monito-ing, hydraulic system monitoring, electrical syitem monitoring, uplink system monitoring, downlink system monitoring, and computer self-test diagnostics operating in the primary computer. The uplink system monitoring and computer selftest diagnostics were duplicated as independent functions in the backup computer. The ground fallure detection and management for the singlestring ground system included down ink integrity testing, uplink integrity testing, real-time loop integrity testing, computer heartbeat monitoring, stfck input checks, I/0 testing, air data testing, and angle-of-attack testing.

\section{AFTI/F..16}

The F-16 airframe is statically unstable in the pitch axis, necessftating a full-time, fullauthority fight control system. The AFTl/F-16 afreraft (Fig. 6) was developed with a triplex, asynchronous flight control system. Goals of this system included dual-fail operate capability and the development of advanced control modes for decoupied motion. The flight contral system consists of three computers, an actuator interface unit, integrated servo actuators, a flight control panel, and assoctated sensors, controllers, and pilot displays (Fig. 7). The system a) so includes a limited triplex analog independent backup unit. The asynchronous flight control computers are identica\} and operate at a frame rate of approximately $16 \mathrm{msec}$, with some functions operating at about 31 and $25 \mathrm{msec}$. The primary sensors (pitch rate gyros, roll rate gyros, and yaw rate gyros) are triply redundant. 
The primary controllers (pitch stick, roll stick, and rudder pedals) operate on three active and one backup transducer. An additional triply redundant controller was added to the throttle (as a throttle twist grip) to provide decoupled pitch control. The primary pilat-vehicle interface consists of two multipurpose displays that provide dual-redundant digital flight control system mode and control status as well as weapons management. The integrated servo actuators contain three electrohydraulic valves operating with two independent hydraulic fluid sources, differential pressure sensing, and LVDT position feedback sensors.

The AFTI/F-16 system contains eight complex modes (Table 2) with multiple submodes controlled by internal switching within the primary modes. These submode switches. in combination with the asynchronous operation of the system generated difficulties in both ground and flight test. Because of the static instability of the pltch axis, all the longitudinal modes require pitch feedback, in cruise conditions as well as takeoff and landing. The standard normal mode is used for takeoff and landing as well as cruise and is the primary digital mode for all failure conditions. Within this standard normal mode are conditions that allow the control laws to reconfigure for sensor and controller failures, which were never flight tested, as well as for landing and takeoff conditions. Along with the primary standard norma 1 mode, three other standard modes are implemented to provide task-tailored control, air-to-air gun mode, air-to-surface gun mode, and air-to-surface bomb mode. Each of these modes, including the standard normal mode, have decoupled counterparts that can be selected through a switch on the sidestick controller. These modes, with the exception of the no-fail condition of the standard normal mode, contain multiple conditions for submode switching. The various modes and their command options are shown in Table 2. The decoupled modes allow independent control of specific derodynamic parameters, such as angle of attack, angle of sideslip, pitch attitude, and yaw attitude, as shown in Fig. 8 .

To deal with the asynchronous interactions and the dual-fail operate goal using a triplex system, the redundancy management software design for the AFTI/F-16 flight control system is as complex as the control law design. Software input voting for the redundant sensors, output voting for actuator commands and status, health checking of computer hardware, and preflight systems monitoring are the major elements of the failure management: system. The input sensors, controllers, and discretes are hardwired into each computer channel and then digitally transmitted between each asynchronous channel. The channels then independently select the appropriate input by averaging the nonfailed like sensors. The output commands for all surfaces are transmitted to each channel and selected, much like the input sensor signals. Unlike the input sensor algorithm, the output command selection chooses a single channe?'s output as deterinined by internal logic. This output selection method was developed to maintain reasonable trip levels in the asynchronous system with reduced nuisance failures at the actuator level. Output command faflures are used to identify a failed computer; two surface command failures in a given channel indicate a defective channel, and all surface commands are assumed fajled in that channel. A detected fallure is reported to the faflure manager. which then takes the appropriate action. The preflight monttoring uses both passive and active testing to determine the status of the flight control computers, actuators, various input sensors and controllers, and the analog backup system. A reset capability is included to allow the processor to reset a transient failure or for nuisance failures caused by asynchronous data transfer in any of the flight contral system input sensors, controllers, actuators, or processors. An independent $1 / 0$ capability is included in the redundancy management design of the AFTI/F-16 fight control system to allow the loss of oniy the processor, not the $1 / 0$ information, in the event of a digital channel fallure. The transition to the analog independent backup unit occurs only if the system cannot determine which of the two remaining channels is good after an output failure or self-test failure detection.

\section{Test Experience}

All the flight control systems described in this paper experienced extensive verification and validation and ground testing prior to being flight tested. In this section, the results of testing for each flight control system (after the elimination of coding errors, which are not discussed here) are compared and evaluated against the criteria discussed previously: reliability, costs, and schedule delays. The results of formal verification and validation testing, onaircraft ground testing, and flight testing are included. Short descriptions of the actual testing are included as background to the test res'slts themselves.

\section{F-8 DFBW}

As a new and untried experiment, the F-8 DFBW fli jht control system went through extensive analysis (described in detall in Ref. 1) before and during the design process in order to validate the design: this level of analysis greatly facilitated the testing. The actual system testing was broken into two areas, subsystem testing and integrated system testing, both of which included breadboard, iron bird, and flight testing. The verification and validation testing consisted of independent system testing, stress testing, and fdilure modes and effects testing. The majority of the independent system testing for the F-8 DFBW design at Ames-oryden was done on the iron bira and covered control laws, executive, computer I/0, computer redundancy management, sensor redundancy management, in-flight self-test, preflight test, displays and controls, primary-bypass system transfer laws, and downlink system. Because the synchronization was critical to the system operation, extensive synchronization testing was done, including tests of the time required for all channels to acquire sync and tests of skew between channels as they exited the sync routine. Occasionally during early testing, a channel sporadically lost sync, or all three channels failed to achieve sync upon power up; consequently, the software was modified. The 
failures were due to synchronization being scheduled at a point that was subject to timing variations. The skew measurements indicated that a value of less then $10 \mu \mathrm{sec}$ was typical. Another anomaly discovered during the early stages of testing was a failure of the system to downmode to the computer bypass system after a dual failure of the input data line. The early detection of these anomalies minimized their impact on costs and schedule.

The next level of testing involved stress testing, a sequence of operations often not considered in the design phase and one that exposes problems not readily apparent in previous tests. The majority of the problems found by stress testing were related to the restart recovery process of the F-8 DFBW system. The anomalies discovered through stress testing had a greater impact on cost and schedule than those discovered during Independent systent tests, but they were discovered early enough in the cycle to minimize the impact. The minor anomalies from the piloted failure modes and effects testing (such as the slow detection of open fallures of stick and rudder inputs and runaway rudder trim) had little impact on both costs and schedule. All the software errors discovered during the verification and validation testing were corrected and retested satisfactorily prior to the on-alreraft ground testing. Table 3 summarizes the anomalies discovered during verification and validation testing and their impact on costs and schedule.

Frecuent channel failures were caused by computer hardware problems during the on-aircraft integration test and continued for the duration of the program. The flight test results for the program were excellent, with very few problems. Anomalies discovered during flight test included three single-channel hard fallures due to hardware faults and one transient channel fault. No software anomalles were discovered in flight, but several were discovered in either ground operation or postflight analysis of the F-8 DFBW flight test data. None of the errors discovered invalidated the fail-operate requirements of the digital flight control system, and no nuisance faults, aside from hardware-related problems, occurred. The software anomalies detected in the approximately $1750 \mathrm{hr}$ of flight time and postflight analysis are shown in Tabie 3 along with thetr impact on costs and schedule. Testing on the F-8 DFBW, both prior to and during flight test, did not reveal a large number of anomalles, indicating high software reliability and low cost and schedule impacts.

REBUS

In both ground and flight testing of the REBUS system, no anomalies occurred. Prior to flight, an evaluation of the transfent response of the alrcraft on reversion to REBUS was made; no translents were considered to be severe, which was verifted in flight. The two pilots who evaluated REBUS felt that it was acceptable for emergency operations and that it was an improvement on the computer bypass mode. Table 4 summarizes the impacts on reliability, costs, and schedule of the Rl:BUS firght control system.
HIMAT

The HIMAT flight control system went through several levels of tests (to be described in detall in the Kempel and Earis report, in preparation) to qualify the system for flight. Each subsystem, each subsystem interface, and the integrated system were tested utilizing test configurations that varied from an all-software simulation to an iron bird simulation. The iron bird simulation included all the actual hardware and software used during a flight and the HiMAT vehicle. The testing included verification and validation (consisting of subsystem functional tests, failure modes and effects tests, and time delay tests), on-aircraft ground tests (consisting of closed-loop control system tests, limit cycle tests, ground resonance tests, and preflight tests), and flight test.

Problems in both hardware and software were revealed during the testing. Two major anomalies were discovered during the on-aircraft ground testing: First, asynchronous operation in combination with the high data rate from the ground-based uplink caused a fallure of the onboard computer. The onboard computer spent too much time servicing the uplink and did not accomplish other critical tasks. Second, hard fallures in the uplink system were interpreted as intermittent faflures by the onboard computers because the persistence counter was being incremented after the maximum persistence count had been reached. The counter in the onboard computer would eventually wrap around, and the fallure would be reset to be declared falled again when the counter reached the maximum persistence count again. Both of these anomalies were corrected prior to flight test, the first through a hardware modification and the second through a software modification. Both anomalies were discovered after verification and validation but prior to flight test, thus requiring time to modtfy and retest.

Flight test of the HiMAT system revealed three anomalies, one with major impact to the program. Transient fallures occurring in flight would reset faster than coulo be detected by the monitoring engineer. A latch was added on the ground to keep the transient faflures displayed long enough for the fallure to be detected by the responsible engineer. Another minor anomaly involved round-off errors in the onboard computer; the pilot had to advance the throttle past the minimum afterburner position to get the afterburner to light. A software change was implemented in the onboard computer, al lowing normal operation of the throttle. Both of these anomalles were nuisance problems and did not prevent operation of the system. However, a timing problem was discovered in flight that resulted in a gear-up landing, having major impact on the project. One of the uplink decoders failed, and the onboard computer would not accept the automatic sequence of commands required to lower the landing gear. This fallure condition was caused by the change in filterting applied to the uplink signals when that decoder falled. If the other decoder had been the one to fafl, the filtering would not have been affected, and the problem could possibly 
have gone undetected. Again, the onboard computer software was changed to correct the problem.

The majority of these anomalies discovered during testing were related to the interfaces between different components of the asynchronous system. These types of problems can be detected only in an integrated environment that exercises the system in the same way it will be used during flight. Table 5 summarizes the HiMAT anomalies and their impact on reliability, costs, and schedule dellays.

AFTI $1 / F .16$

The AFTI/F-16 system began verification and validation testing prior to completion of the software integration and debug stage; however, testing did not of ficially begin until all the coding errors in the system had been tested and corrected. Early in the testing process it was discovered that the high-gain control laws were interacting adversely with the redundancy management software. This interaction magnified the differences in input values resulting from asynchronous skew to create output and channel failure. After the gains were reduced, output and channel failures still occurred. The gain magnification of input differences exceeded the output tolerance during dynamic maneuvers, resulting in the addition of a rate-of-change factor to adjust the output tolerance. Both conditions were discovered prior to the actual verification and validation and had minor impacts on both costs and schedule. Major anomalies discovered during the verification and validation testing included air data and bus contentior anomalies. An undetected bias failure in air data below the 15-percent trip level would cause channel failures; a bus controller contention problem could cause loss of the digftal flight control system. Both anomalies required sof tware modifications but were discovered early enough in the project development to have only moderate effects on costs and schedule.

Greater costs and schedule delays were incurred from the results of the ground gunfire tests. The vibration in the lateral accelerations and yaw rate from the gun firing caused output and channel failures because of the highgain magnification. The time required to modify and retest the software prior to flight test generatied a delay in the schedule. Flight test results of the AFTI/F-16 system included nine flight control system failures in 177.2 flight hours. All these failures resulted in either an interruption of the mission, with some points not flown, or a return and land requirement. Seven of the inuflight errors were the result of asynchronous skew effects on submode switching; each channel would trigger a change in a submode switch at different times, resulting in output failures and channel failures. Several of the failure conditions delayed the next flight by one or more days and reduced the allowable flight envelope or eliminated a mode. Two of the inflight failures were transient failures that could not be duplicated and did not reoccur; considerable engineering time was lost in the duplication attempt. Another in-flight fallure was the result of an avionics failure, not a fallure of the flight control system. The avionics system failure induced random mode changes in the flight control system at very high rates; consequently, the flight was discontinued, and the aircraft returned and landed. A software modification was made to the digital flight control system (rather than to the avionics) to prevent a reoccurrence because the faiture could not be duplicated and did not reoccur. One major result of the first phase of the AFTI/F-16 program was that throughout the flight test program no failure caused a reversion to the independent backup mode. The failures discovered during the testing of the AFTI/F-16 system are summarized in Table 6 along with their impact on the software reliability, costs, and schedule.

\section{Digital Flight Control Systems Evaluation}

All four airciraft completed successful flight test programs with the number of anomalies occurring varying from one program to another. The four digital flight control systems, F-8 DFBW, REBUS, HIMAT, and AFTI/F-16, are evaluated in relationship to software reliability, increased costs, and schedule delays. Software reliability, defined as the inverse of the number of in-flight nonnuisance failures, was high on all the flight control systems, and all systems were proven safe throughout their flight envelopes. The F-8 DFBW aircraft experienced no software-related problems in flight, though some were discovered in postflight analysis. The REBUS system exhibited no anomalies during ground or flight test. The HIMAT system had one major in-flight anomaly, which resulted in a gear-up landing on the lakebed, and two minor anomalies. The AFTI/F-16 aircraft experienced nine in-flight anomalies during the first phase of the program. In terms of reliability, the two highly complex, asynchronous systems, the HIMAT and AFTI/F-16, had the most in-flight anomalies.

Seven of the nine AFTI/F-16 anomalies were due to a combination of asynchronous operation, complex control laws, and complex redundancy management design. These problems were related to the procedure of crosslinking data between channels and then using good-channel average; the skew between channels was often just sufficient to cause the channels to use inputs differing enough that output fallures or channel fallures, or both, resulted. The asynchronous operation of the AFTI/F-16 system increased the complexity of its flight control system. The design of the REBUS system intentionally avoided many of the problems associated with the asynchronous effect on crosslinked data. The REBUS system was able to avoid these effects by not crosslinking any data and allowing each channel to operate independentiy on independent inputs, with the commands evaluated in the actuators instead of in the filight control software. The REBUS was also developed as a simple system to remove extra complexity that could adversely affect the asynchronous operation. The synchronous operation of the F-8 OFBW flight control system assured that each channel operated on the same data at the same time, therefore output failures due to data crosslinking and skew conditions could not occur. The HIMAT system's major in-flight anomaly was due to a timing problem when the uplink 
decoder failed. The complexity of the AFTI/F-16 and HiPMT systems made it difficult to predict and test all the conditions prior to flight. Two assessments that can be made from these results are thai complexity is a major factor in flight control system software relfability and that synchronization and asynchronization do not, by themselves, determine relfability.

Increased costs and schedule delays (related in that schedule delays increase the cost of a system) were encountered by all the systems to differing degrees. The AFTI/F-16 testing did not originally allow variation of skew conditions nur were the skew conditions measured during the early tests. Consequently, there was no method for determining or setting the exact test condition, which varied from one test point to another. Additional testing was then required to repeat and correct anomalles, incurring schedule delays and increased costs. As the program progressed and several anomalies occurred in litght, the capabllfty of adjusting the skew conditions was included into the test factlity for the AFTI/F-16 system. A related factor involved in the schedule delays and increased costs was the difficulty with the asynchronous operation in determining which skew conditions were actually worst case for which flight conditions. The AFTI/F-16 system, with its complicated gain structure, had varying gains at each flight condttion, which presented difficulties in determining worst-case conditions. Skew effects were evaluated early to determine the tolerance values, not to determine worst-case skew at different flight conditions and different modes. The very large matrix that would need to be evaluated discouraged the evaluation. The difficulty connected with worst-case skew predictlon resulted in continuously repeating a test condition until the anomaly reoccurred. With a simpler system, a thorough evaluation of different skew conditions would have been possible, allowing the elimination of problems early in the design process, thus reducing schedule delays and cost increases. The REBUS program avoided these difficulties by using a simple system. The skew on the REBUS system was monitored, and the results of both flight and ground tests indicated very little variation, which when combined with the simple design resulted in no difficulties with the asynchronous system. The F-8 DFBW flight control system testing was fairly stralghtforward, with an easily defined test matrix. The test matrix did not need to be expanded to account for different skew conditions. Some design problems were addressed early in the $F-8$ OFBW flight control system verification and validation stage, but they had minimal impact on both cost and schedule. The synchronization of the computers for the system created some difficulties, but once the timing problems were corrected, no further anomalies arose. One inference is that asynchronous systems need to be simple to avoid increased testing and protect against in-filght anomalles.

Another factor to be considered in minimizing schedule: delays and cost increases is the system developnent of the digital flight control system as an integrated system. The F-8 DFBW and HiMAT systems were developed as integrated systems: all the interfaces were developed along with the flight control system. With this integrated design, the problems associated with interfaces and interactions were greatly reduced. This is reflected in the low anomaly rate during flight. and ground tests of these systems. The AFTI/F-16 filight control system was developed separately from many of its interfaces, and consequently, the testing process revealed a number of anomalies that resulted from the interactions between systems. The integration-related anomalies continued through ground test, as evidenced by the ground gunfire fallures, and in flight, as in the multiple-mode switching anomaly. While the asynchronous operation of the AFTI/F-16 system Impacted these anomalles, the integrated environment had a larger effect. The integrated design process was especially helpful for the HiMAT vehicle. A tightly knit group of people developed the HiMAT systems together, which allowed close communication and problem resolution early in the development cycle. The HiMAT systems were viewed as a large system with many subsystems, and an effort was made to insure that all the interfaces were properly integrated. The early integration in an environment that exercised the system in the same way as it would be in flight allowed the resolution of anomalies prior to flight and minimized schedule delays and cost increases.

\section{Concluding Remarks}

The AFTI/F-16 system was very complex in its control laws and redundancy management design. Its asynchronous operation coupled with a goal of dual-fail operate for a triplex system and the multimoded, complicated control structure resulted in a series of both in-flight and ground test anomalies. The HiMAT system, also complex, was tested in an integrated environment that closely simulated the flight environment, thus allowing early detection of potential problems and mintmizing in-flight anomalies. The REBUS system had a very simple control structure and 1 imited the data crosslink to avold problems associated with asynchronous operation. The F-8 DFBW system, while not extremely complex, had sufficient complications to show that for some situations a synchronous system may be better for complex systems. As an integrated design, the F-8 DFBW system avoided problems that could have occurred and resulted in a highly successful and relatively trouble-free test prográm.

The evaluation of the F-8 DFBW, REBUS, HIMAT, and AFTI/F-16 flight control systems lead to some interesting conclusions:

1. The asynchronous or synchronous operation of the systems was not in itself a determining factor in the number of anomalies and difficulties encountered during testing.

2. The complexity of the system can cause major impacts in terms of anomalies during both ground and flight testing.

3. A simple asynchronous system without a complicated data crosslink structure may be easier to develop than a synchronous system of the same magnitude. 
4. A system designed as an integrated system, including all interactions and interfaces, has a reduced level of difficulties in testing and operation.

\section{References}

${ }^{1}$ Sialai, Kenneth J., Jarvis, Caivin R., Krier,

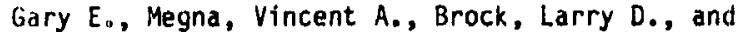
0'Donneil, Robert. N., "Digital Fly-By-Wire Flight Control Validation Experience." NASA TM-72860, 1978.
2Deet5, Dwain A., Lock, Wilton $P_{.}$, and Megna, Vincent. $A_{*}$, "Flight Test of a Resident Backup Software System," NASA TM-86807, 1986.

Is hmael, Stephen D., Regenie, Victoria A., and Mackall, Dale A., "Design Implications From AFTI/F-16 Filight Test," NASA TM-86026, 1984.

4Joyner, Capt. Mark L., and Heimple, Lt. Col. Harry H., "AFTI/F-16 Digital Flight Control Sys.tem Evaluation," AFFTC-TR-83-48, Dec. 1983.

Table I HiMAT backup filight control system modes and functional characteristics

\begin{tabular}{|c|c|}
\hline Mode & Mode function \\
\hline Recovery & $\begin{array}{l}\text { Backup control system Inftialized in this mode } \\
\text { Brings the vehicle to level flight }(\dot{h}=0 \mathrm{ft} / \mathrm{min})\end{array}$ \\
\hline Orbit & $\begin{array}{l}\text { Orbft mode will be entered at expiration of } 25-\mathrm{sec} \\
\text { timer following transfer to backup control system } \\
\text { (unless exit orbit has been selected) } \\
\text { vehicle will climb to one of three orbit altitudes } \\
\text { or dive to } 25,000 \mathrm{ft} \text { if backup control system } \\
\text { is entered above this altitude } \\
\text { Orbit altitudes are } 25,000 \mathrm{ft}, 10,000 \mathrm{ft} \text {, and } 5000 \mathrm{ft}\end{array}$ \\
\hline Strafght and level & Altitude, quasi-heading, and speed or Mach hold \\
\hline Turn 1 & $\begin{array}{l}\text { Att itude command roll rate } \\
\text { Roll rate command roll rate }\end{array}$ \\
\hline Turn 2 & $\begin{array}{l}\text { All climbs at, } 100 \mathrm{ft} / \mathrm{sec} \\
\text { Dives above } 10,000 \mathrm{ft} \text { at } 100 \mathrm{ft} / \mathrm{sec} \\
\text { Dives below } 10,000 \mathrm{ft} \text { at } 60 \mathrm{ft} / \mathrm{sec}\end{array}$ \\
\hline Land & $\begin{array}{l}\text { Scheduled airspeed and altitude rate command as a } \\
\text { function of radar altitude } \\
\text { Pilot is able to modulate airspeed and altitude } \\
\text { rate within ilmits; minimum airspeed is } 185 \text { knots } \\
\text { Alternative land mode provided in the event of } \\
\text { radar altimeter failure }\end{array}$ \\
\hline $\begin{array}{l}\text { Engine-out glide } \\
\text { and flare }\end{array}$ & $\begin{array}{l}\text { Commanded airspeed of } 215 \text { knots with modulation } \\
\text { capability } \\
\text { Flare initiated at } 550 \mathrm{ft} \text { radar altitude with } \\
\text { elevon control transfers from airspeed comand } \\
\text { to altitude rate command }\end{array}$ \\
\hline
\end{tabular}


Table 2 AFTI/F-16 system modes and command options

\begin{tabular}{|c|c|c|c|c|c|}
\hline \multirow{3}{*}{ Mode } & \multicolumn{5}{|c|}{ Controller } \\
\hline & Pitch stick & Roll & stick & Rudder pedal & Thrattle twist \\
\hline & \multicolumn{5}{|c|}{ Command option } \\
\hline $\begin{array}{l}\text { Standard normal } \\
\text { Standard air-to-surface } \\
\text { bombing }\end{array}$ & $\begin{array}{l}\text { Normal acceleration } \\
\text { Normal acceleration }\end{array}$ & $\begin{array}{l}\text { Roll } \\
\text { Roll }\end{array}$ & $\begin{array}{l}\text { rate } \\
\text { rate }\end{array}$ & $\begin{array}{l}\text { Rudder deflection } \\
\text { Flat turn }\end{array}$ & $\begin{array}{l}\text { None } \\
\text { None }\end{array}$ \\
\hline $\begin{array}{l}\text { Standard air-to-surface } \\
\text { gun }\end{array}$ & Pitch rate & Roll & rate & Flat turn & None \\
\hline $\begin{array}{l}\text { Standard air-to-air gun } \\
\text { Decoupled normal }\end{array}$ & $\begin{array}{l}\text { Pitch rate } \\
\text { Flightpath maneuver } \\
\text { enhancement }\end{array}$ & $\begin{array}{l}\text { Roll } \\
\text { Roll }\end{array}$ & $\begin{array}{l}\text { rate } \\
\text { rate }\end{array}$ & $\begin{array}{l}\text { Flat turn } \\
\text { Translation }\end{array}$ & $\begin{array}{l}\text { None } \\
\text { Translation }\end{array}$ \\
\hline $\begin{array}{l}\text { Decoupled air-to-surface } \\
\text { bombing }\end{array}$ & $\begin{array}{l}\text { Flightpath maneuver } \\
\text { enhancement }\end{array}$ & Rol? & rate & Flat turn & Direct lift \\
\hline $\begin{array}{l}\text { Decoupled air-to-surface } \\
\text { gun }\end{array}$ & $\begin{array}{l}\text { Pitch rate maneuver } \\
\text { enhancement }\end{array}$ & Roll & rate. & Pointing & Pointing \\
\hline Decoupled airato-air gun & $\begin{array}{l}\text { Pitch rate maneuver } \\
\text { enhancement and } \\
\text { flightpath maneu- } \\
\text { ver enhancement }\end{array}$ & Roll & rate & Pointing & Pointing \\
\hline
\end{tabular}

Table 3 Major F-8 DFBW system test anomalies

\begin{tabular}{|c|c|c|c|c|}
\hline \multirow{2}{*}{ Test type } & \multirow{2}{*}{ Anomalfes } & \multicolumn{3}{|c|}{ Impact } \\
\hline & & Reliability & Costs & Schedule \\
\hline $\begin{array}{l}\text { Verification and } \\
\text { validation }\end{array}$ & $\begin{array}{l}\text { Continued operation for some } \\
\text { sync faults } \\
\text { No CBS downmode for dual input } \\
\text { data line failure } \\
\text { software problem in power } \\
\text { recovery process }\end{array}$ & -- & $\begin{array}{l}\text { Low } \\
\text { Low } \\
\text { Low }\end{array}$ & $\begin{array}{l}\text { Low } \\
\text { Low } \\
\text { Low }\end{array}$ \\
\hline $\begin{array}{l}\text { Ground test and } \\
\text { operation }\end{array}$ & $\begin{array}{l}\text { Sensor fault logic errors } \\
\text { Incorrect internal interrupt } \\
\text { handing }\end{array}$ & 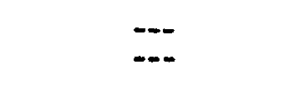 & $\begin{array}{l}\text { Moderate } \\
\text { Moderate }\end{array}$ & $\begin{array}{l}\text { Moderate } \\
\text { Moderate }\end{array}$ \\
\hline Flight test & None & Positive & None & None \\
\hline $\begin{array}{l}\text { Analysis of ground and } \\
\text { flight test data }\end{array}$ & $\begin{array}{l}\text { Fault detection logic design error } \\
\text { Fault recovery logic deficiency }\end{array}$ & $\begin{array}{l}\text { Moderately negat ive } \\
\text { Moderately negat ive }\end{array}$ & $\begin{array}{l}\text { Moderate } \\
\text { Moderate }\end{array}$ & $\begin{array}{l}\text { Moderate } \\
\text { Moderate }\end{array}$ \\
\hline
\end{tabular}

Table 4 REBUS system test results

\begin{tabular}{|c|c|c|c|c|}
\hline \multirow{2}{*}{ Test type } & \multirow{2}{*}{ Anomalies } & \multicolumn{3}{|c|}{ Impact } \\
\hline & & Reliabllity & Costs & Schedule \\
\hline $\begin{array}{l}\text { Verification and validation } \\
\text { Ground test and operation } \\
\text { Flight test }\end{array}$ & $\begin{array}{l}\text { Minor } \\
\text { None } \\
\text { None }\end{array}$ & Positive & $\begin{array}{l}\text { Low } \\
\text { None } \\
\text { None }\end{array}$ & $\begin{array}{l}\text { Low } \\
\text { None } \\
\text { None }\end{array}$ \\
\hline
\end{tabular}


Table 5 HilAT system major test anomalies

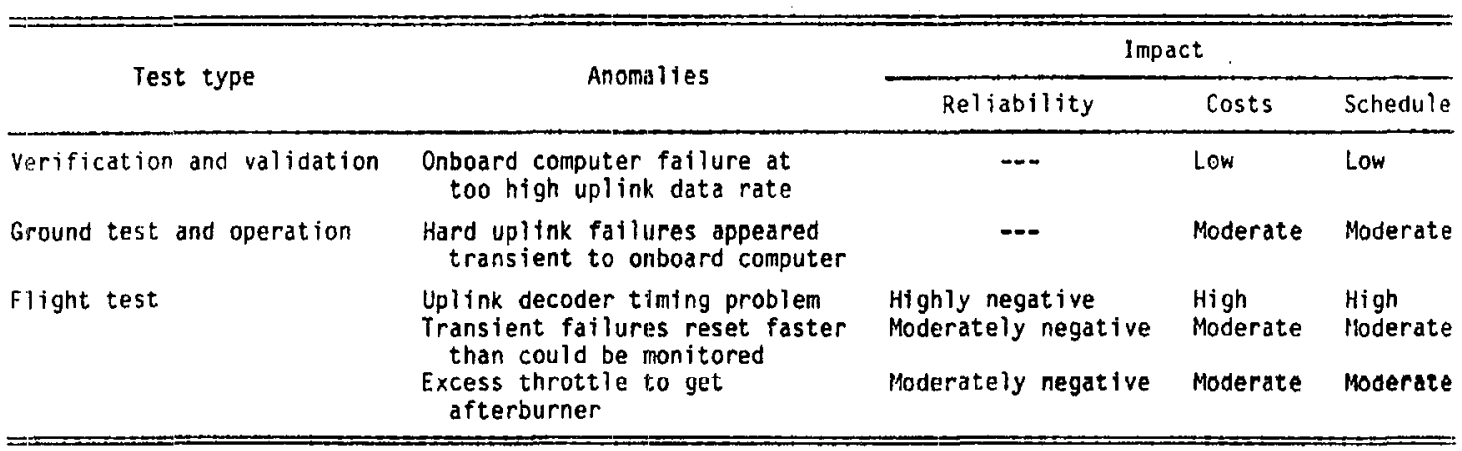

Table 6 AFTI/F-16 system major test anomalies

\begin{tabular}{|c|c|c|c|c|}
\hline & Anomalies & Reliability & Costs & Schedule \\
\hline $\begin{array}{l}\text { Verification and } \\
\text { validation }\end{array}$ & $\begin{array}{l}\text { Output and channel failures due } \\
\text { to high gains } \\
\text { Low output toleranses in dynamic } \\
\text { maneuvers } \\
\text { Channel failure due to air data bias } \\
\text { Bus contention caused.channel failure }\end{array}$ & $\begin{array}{l}\cdots \\
\cdots \\
\cdots \\
\cdots-\end{array}$ & $\begin{array}{l}\text { Low } \\
\text { Low } \\
\text { Low } \\
\text { Low }\end{array}$ & $\begin{array}{l}\text { Low } \\
\text { Low } \\
\text { Low } \\
\text { Low }\end{array}$ \\
\hline Ground test and operation & $\begin{array}{l}\text { Output and channel failure during } \\
\text { gunfire test }\end{array}$ & $\cdots$ & Moderate & Moderate \\
\hline Flight test & $\begin{array}{l}\text { Leading edge flap output command } \\
\text { fallure } \\
\text { Channel failure due to three output } \\
\text { command failures in one channel } \\
\text { Left and right canard output failures } \\
\text { Dual channel fallure due to dual } \\
\text { output command failure } \\
\text { Left and right flaperon output } \\
\text { command failures } \\
\text { Left and right canard output faflures } \\
\text { Channel failure due to three output } \\
\text { command fallures in one channel } \\
\text { Multiple-mode switching due to } \\
\text { avionics fault }\end{array}$ & $\begin{array}{l}\text { Highly negative } \\
\text { Highly negative } \\
\text { Highly negative } \\
\text { Highly negative } \\
\text { Highly negative } \\
\text { Highly negative } \\
\text { Highly negative } \\
\text { Highly negative }\end{array}$ & $\begin{array}{l}\text { High } \\
\text { High } \\
\text { High } \\
\text { High } \\
\text { High } \\
\text { High } \\
\text { High } \\
\text { High }\end{array}$ & $\begin{array}{l}\text { High } \\
\text { High } \\
\text { High } \\
\text { High } \\
\text { High } \\
\text { High } \\
\text { High } \\
\text { High }\end{array}$ \\
\hline
\end{tabular}




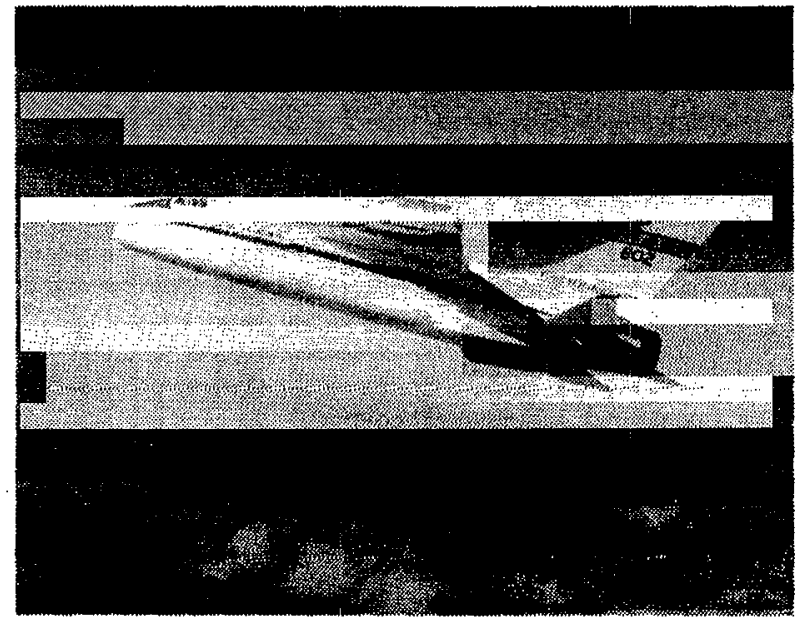

ECN 3312

Fig. 1 F-8 DFBW aircraft.

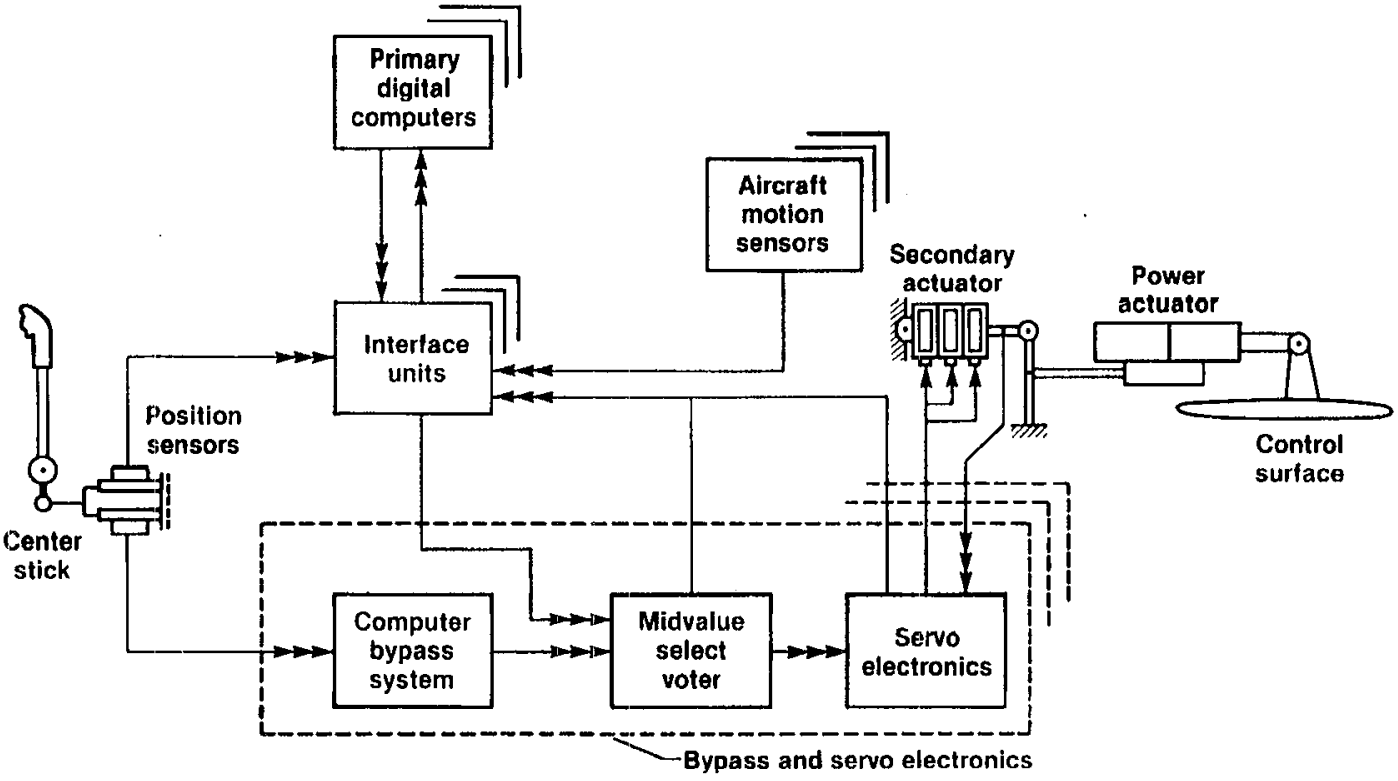

Fig. 2 F-8 DFBW flight control system. 


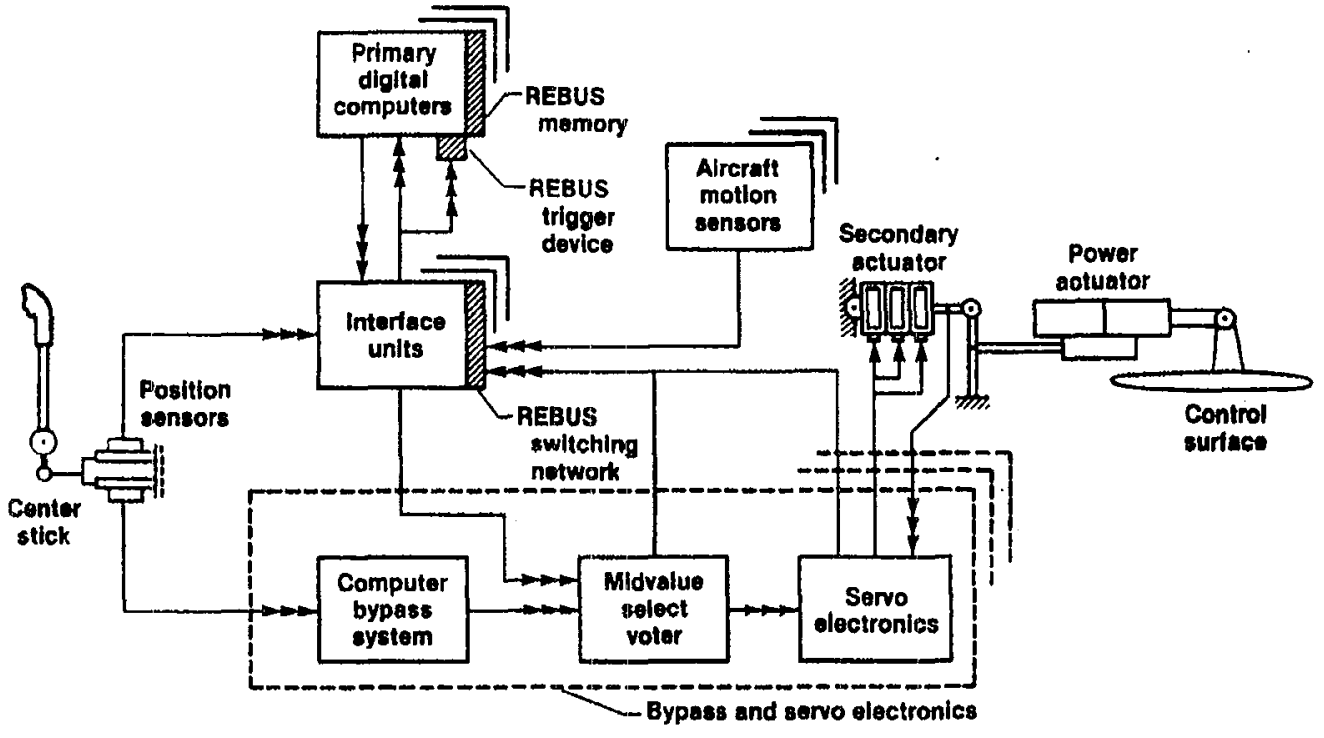

Fig. 3 REBUS implamentation on the F-8 DEBW aircraft.

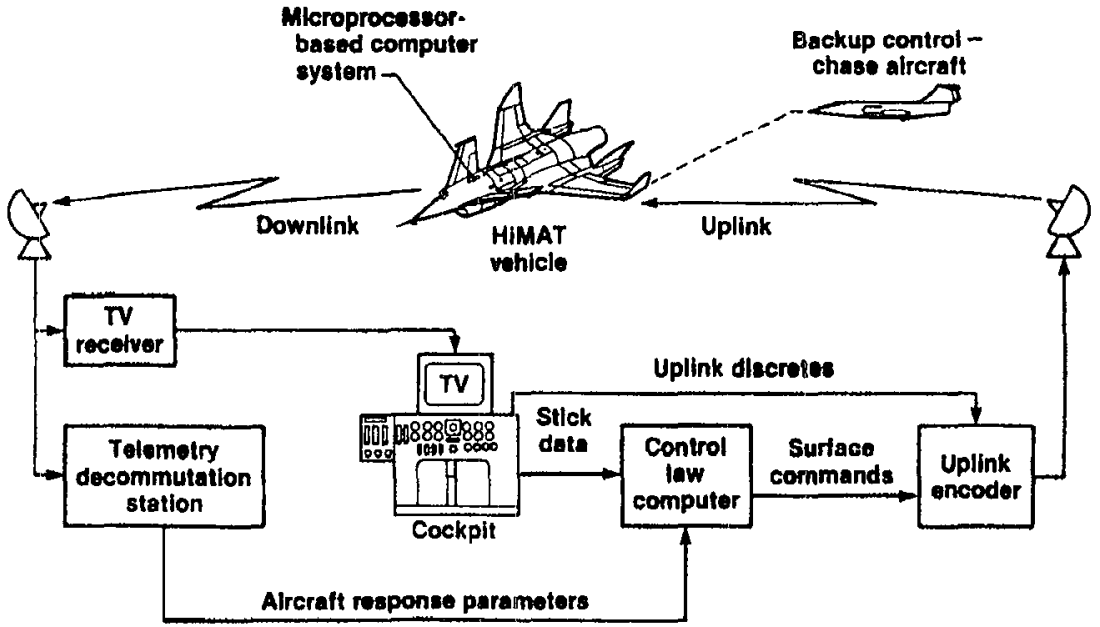

Fig. I HiMAT KREV control eystem. 


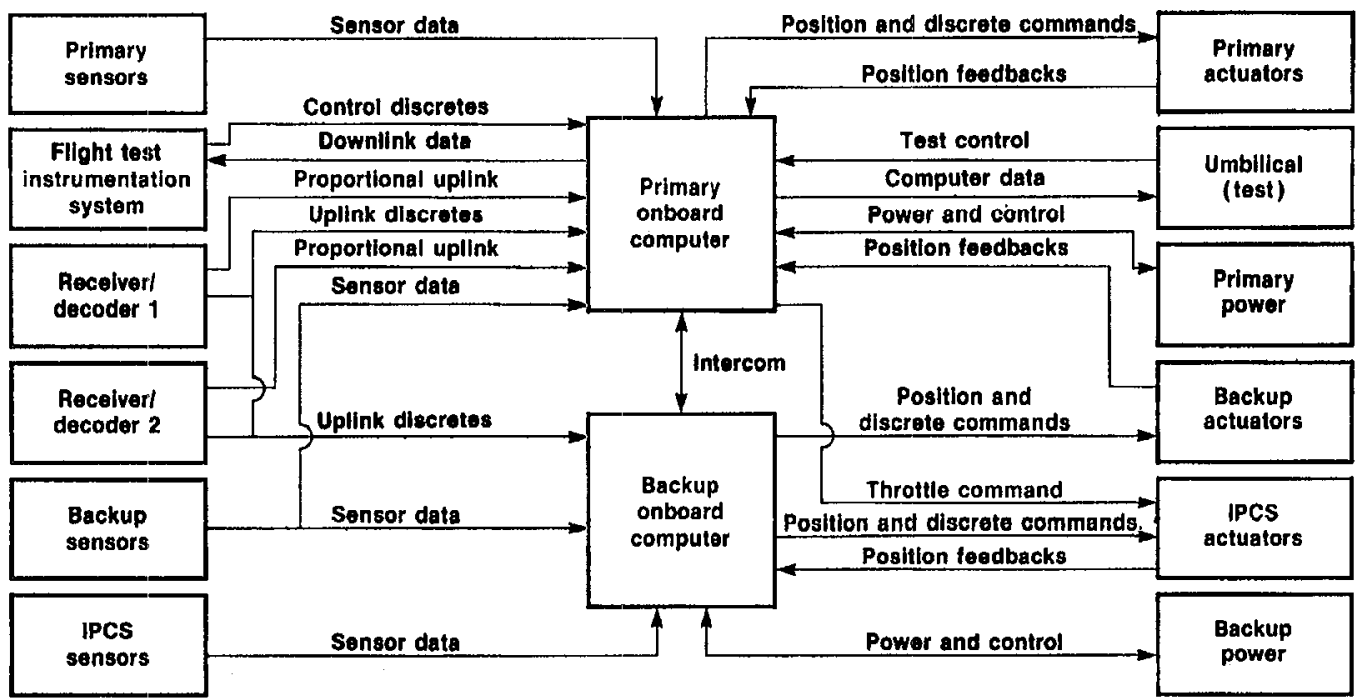

Fig. 5 HiMAT airborne computer-aircraft aysteme interface diagram.

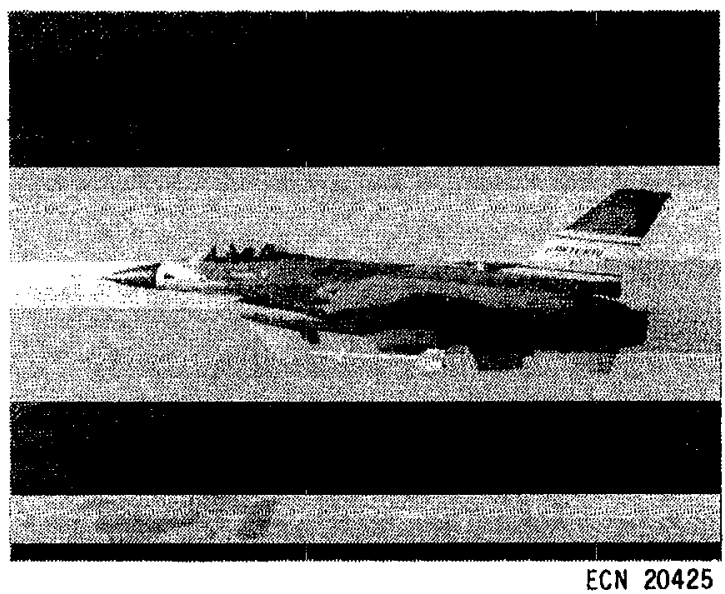

Fig. 6 AFTI/F-16 airoraft. 


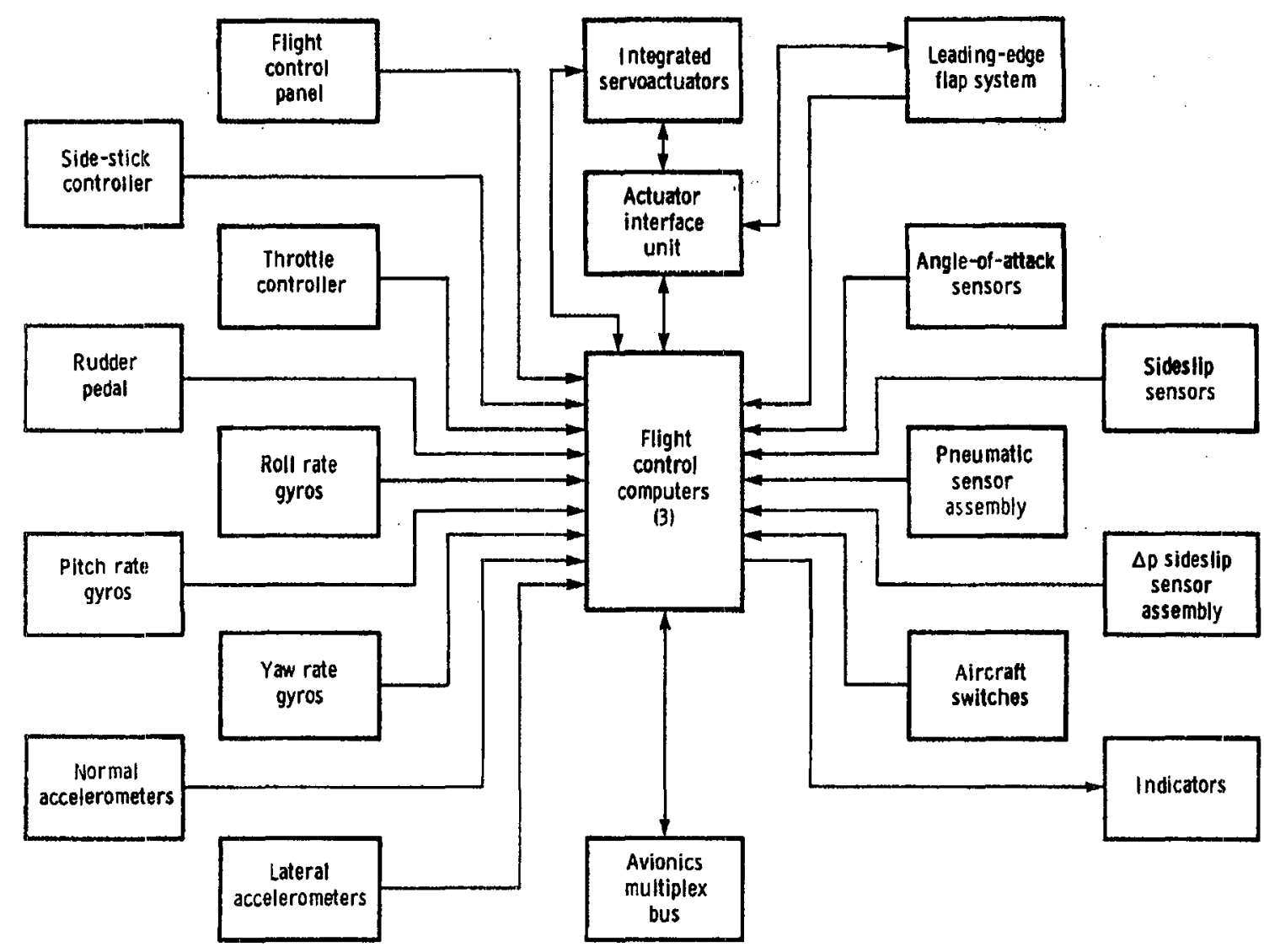

Fig. 7 AMI/F-16 flight control aystem. 

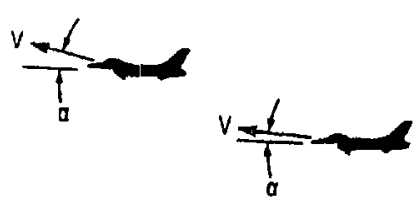

(a) Vertical translation: vertical velocity control at constant pitch attitude.
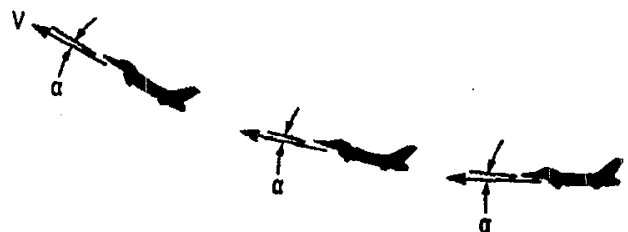

(b) Direct lift; vertical flightpath control at constant angle of attack.
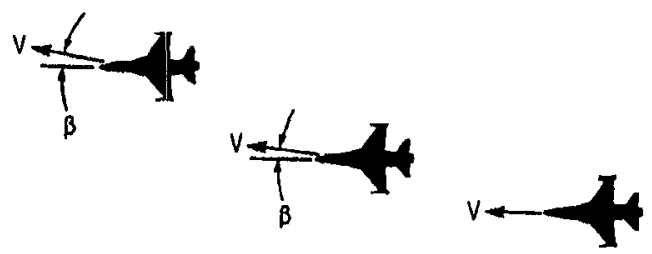

(d) Lateral translation: lateral volocity control at constant yaw attitude.
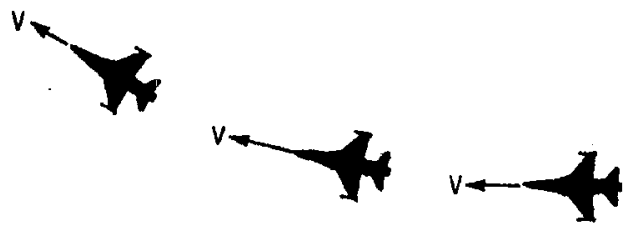

(o) Direst sideforce: directional flightpath control at sero oideslip angle.

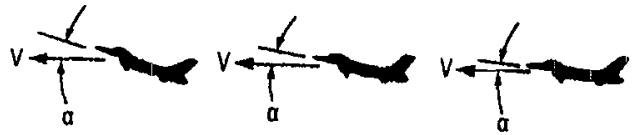

(a) Pitch pointing: pitch attitude control at conotant flightpath angle.

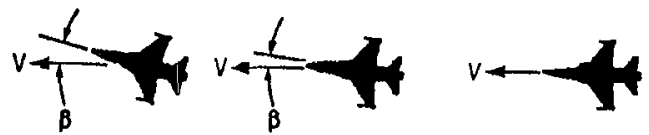

(f) Yaw pointing: directional attitude control at conetant flightpath angle.

Fig. \& AFTI/F-16 desoupled control. 


\begin{tabular}{|c|c|c|c|}
\hline $\begin{array}{l}\text { 1. Hepor: No. } \\
\text { NASA TH- } 88271\end{array}$ & 2. Government Accession No. & \multicolumn{2}{|c|}{ 3. Recipient's Coralog No. } \\
\hline \multicolumn{2}{|l|}{ 4. Thle and Subtitie } & \multicolumn{2}{|c|}{$\begin{array}{l}\text { 5. Aeport Oate } \\
\text { August } 1986\end{array}$} \\
\hline \multicolumn{2}{|c|}{$\begin{array}{l}\text { EXPERIENCE WITH SYNCHRONOUS AND } \\
\text { ASYNCHRONOUS DIGITAL CONTROL SYSTEMS }\end{array}$} & \multicolumn{2}{|c|}{ 6. Performing Orgonization Code } \\
\hline \multicolumn{2}{|c|}{$\begin{array}{l}\text { 7. Author(s) } \\
\text { Victoria A. Regenie, Claude V. Chacon, } \\
\text { and Wilton P. Lock }\end{array}$} & \multicolumn{2}{|c|}{$\begin{array}{l}\text { 8. Porforming Orgenization Roport No. } \\
\text { H-1372 }\end{array}$} \\
\hline \multirow{4}{*}{\multicolumn{2}{|c|}{$\begin{array}{l}\text { 9. Performing Organization Name and Addrat } \\
\text { NASA Ames Research Center } \\
\text { Dryden Flight Research Factlity } \\
\text { P.0. Box } 273 \\
\text { Edwards, CA } 93523-5000\end{array}$}} & \multirow{2}{*}{\multicolumn{2}{|c|}{$\begin{array}{l}\text { 10. Work Unli No. } \\
\text { RTOP 505-66-02 }\end{array}$}} \\
\hline & & & \\
\hline & & \multicolumn{2}{|c|}{ 11. Contrect or Grant No. } \\
\hline & & \multirow{2}{*}{\multicolumn{2}{|c|}{$\begin{array}{l}\text { 13. Type of Report and Period Covered } \\
\text { Technical Memorandum }\end{array}$}} \\
\hline \multirow{2}{*}{\multicolumn{2}{|c|}{$\begin{array}{l}\text { 12. Sponsoring Aguncy Name and Address } \\
\text { Nat ional Aeronaut ics and Space Administration } \\
\text { Washington, D.C. } 20546\end{array}$}} & & \\
\hline & & \multicolumn{2}{|c|}{ 14. Sponsoring Ageney Code } \\
\hline \multirow{2}{*}{\multicolumn{4}{|c|}{$\begin{array}{l}\text { 15. Supplementary Notes } \\
\text { Prepared as AIAA-86-2239-CP for presentation at the AIAA Guidance, Navt } \\
\text { Conference. Williamsburg. Vtrginia, August 18-20, 1986. }\end{array}$}} \\
\hline & & & \\
\hline \multirow{2}{*}{\multicolumn{4}{|c|}{$\begin{array}{l}\text { on since the daj } \\
\text { vanced systems } \\
\text { lling unstable } \\
\text { the aerodynamic } \\
\text { erformance and } \\
\text { n and advanced } \\
\text { will be and are } \\
\text { stabflity and } \\
\text { llow the pilot } \\
\text { ave been propose } \\
\text { these advanced } \\
\text { n is whether a } \\
\text { onous or asynchr } \\
\text { the Dryden Flig } \\
\text { h both synchrono } \\
\text { ur different fl } \\
\text { as software rel }\end{array}$}} \\
\hline & & & \\
\hline \multirow{2}{*}{\multicolumn{2}{|c|}{$\begin{array}{l}\text { 17. Key Words (Sugpented by Author(s)) } \\
\text { Asynchronous systems } \\
\text { Digital flight control systems } \\
\text { Flight control system architecture } \\
\text { Synchronous systems }\end{array}$}} & & \\
\hline & & STAR cate & y 08 \\
\hline $\begin{array}{l}\text { 19. Sexurity Classif. lof this reportl } \\
\text { Unclassified }\end{array}$ & $\begin{array}{l}\text { 20. Security Clasulf. (of this papol } \\
\text { Uncl assifited }\end{array}$ & $\begin{array}{l}\text { 21. No. of Pagon } \\
17\end{array}$ & $\begin{array}{l}\text { 22. Price" } \\
\text { A02 }\end{array}$ \\
\hline
\end{tabular}

"For sale by the National reohnioal Information Servioe, Springfield, Virginia 22161. 
End of Document 